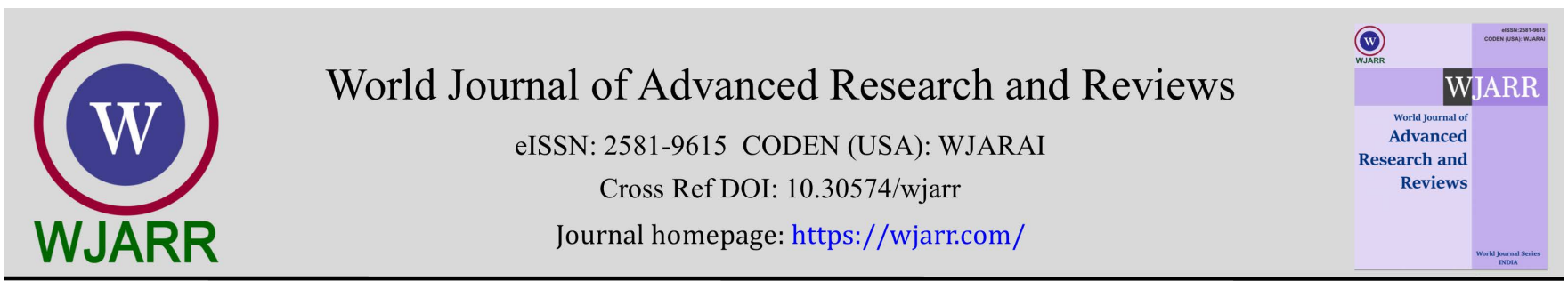

(RESEARCH ARTICLE)

Check for updates

\title{
Prevalence and molecular characterization of extended spectrum beta-lactamase producing uropathogenic Escherichia coli in a tertiary health care facility in Anambra State, Nigeria
}

\author{
Ifeoma G Nwafuluaku 1, 2, ${ }^{\text {, Nneka R Agbakoba }}{ }^{2}$, Simon N Ushie ${ }^{3}$ and Eucharia A Dilibe ${ }^{4}$ \\ ${ }^{1}$ Department of Medical Microbiology and Parasitology, Nnamdi Azikiwe University Teaching Hospital, Nnewi, Anambra \\ State, Nigeria. \\ ${ }^{2}$ Department of Medical Laboratory Science, Faculty of Health Sciences and Technology, Nnamdi Azikiwe University, \\ Nnewi Campus, Anambra State, Nigeria. \\ 3 Department of Medical Microbiology and Parasitology, Nnamdi Azikiwe University, Awka, Anambra State, Nigeria. \\ ${ }^{4}$ Department of Medical Microbiology, Faculty of Basic Clinical Medicine, College of Medicine, Chukwuemeka Odumegwu \\ Ojukwu University, Awka Campus, Anambra State, Nigeria.
}

World Journal of Advanced Research and Reviews, 2021, 11(03), 300-311

Publication history: Received on 18 August 2021; revised on 21 September 2021; accepted on 23 September 2021

Article DOI: https://doi.org/10.30574/wjarr.2021.11.3.0467

\begin{abstract}
Background: The prevalence of ESBLs-producing Escherichia coli has recently increased worldwide due to the expression of ESBL genes which had led to high rate of multidrug resistance antibiotics.
\end{abstract}

Aim: To determine the antimicrobial susceptibility patterns of $E$. coli isolates and evaluating the ESBL carriage of these isolates at phenotypic and genotypic levels.

Methods: One hundred and two clinical Escherichia coli isolates were recovered from UTI suspects and analyzed for ESBL production at phenotypic and genotypic levels using Modified Double Disc Synergy Test and Polymerase Chain Reaction respectively.

Results: Of the 102 isolates, $100(98.04 \%)$ were associated with MDR phenotypes. The isolates showed variable resistance to all the antibiotics used in the study. The resistance rates were $99.0 \%, 97.1 \%, 88.2 \%, 82.4 \%, 81.4 \%, 65.7 \%$, $54.9 \%, 46.1 \%, 46.1 \%, 23.5 \%$ for ampicillin, trimethoprim-sulfamethoxazole, ciprofloxacin, ceftriaxone, ceftazidime, amoxicillin-clavulanate, gentamycin, cefoxitin, nitrofurantoin and imipenem, and respectively. The prevalence of phenotypic ESBL production was 74.5\%. Based on the PCR results, the randomly selected 20 ESBL-positive isolates possessed one or more ESBLs genes. CTX-M type was the predominant ESBLs type (100\%), while those for TEM and SHV-types were $85 \%$ and $80 \%$ respectively. Four genotype patterns were detected (CTX-M, TEM+CTX-M, SHV+CTX-M and SHV+TEM+CTX-M). The genotype SHV+TEM+CTX-M, was the predominant $(70 \%)$, followed by the genotype TEM + CTX-M combination (15\%). The occurrences of the genotypes, CTX-M and SHV+CTX-M were $5 \%$ and $10 \%$ respectively.

Conclusion: This study found a high rate of Phenotypic ESBL production (74.5\%) among the isolates with multidrug resistance, CTX-M as the predominant ESBLs type (100\%) and combination of SHV+TEM+CTX-M as the predominant genotype (70\%).

Keywords: Escherichia coli; Extended spectrum beta-lactamases; Modified double disc synergy test; Anambra State

\footnotetext{
${ }^{*}$ Corresponding author: Ifeoma G Nwafuluaku

Department of Medical Microbiology and Parasitology, Nnamdi Azikiwe University Teaching Hospital, Nnewi, Anambra State, Nigeria.
}

Copyright (@ 2021 Author(s) retain the copyright of this article. This article is published under the terms of the Creative Commons Attribution Liscense 4.0. 


\section{Introduction}

A urinary tract infection (UTI) is a situation in which one or more sites of the urinary system (kidneys, ureters, bladder, and urethra) become infected. Urinary tract infections are a universal health issue in both outpatient and inpatient locations, and urine cultures bear most of the workload in practically all clinical Microbiology laboratories. Approximately $95 \%$ of cases of UTIs are produced by bacteria that consistently proliferate at the orifice of the urethra and navigate up to the bladder. Occasionally, bacteria disseminate to the kidney from the bloodstream. Urinary tract infections are severe public health problems and are caused by a diverse collection of organisms, but frequently by Escherichia coli (E. coli), Klebsiella pneumoniae, Proteus mirabilis, Enterococcus faecalis and Staphylococcus saprophyticus [1]. Extended-spectrum $\beta$-lactamase-producing Enterobacteriaceae is an emerging public health concern. Complications in UTIs have increased because of the prevalence of extended spectrum beta-lactamases (ESBL) producing bacterial pathogens which are also causing many management and epidemiological issues [2].These complications came out from the increasing resistance among UTI pathogens to conventional drugs. Although a wide range of pathogens can cause UTI, E. coli continues to be the most common cause due its ubiquitous presence in the perianal area.

Production of beta-lactamase is one of the most critical mechanisms in Gram-negative bacteria against beta-lactam antibiotics. Due to the treatment of bacterial infections with the broad-spectrum antibiotics, it leads to the production ofbroad-spectrum enzymes called beta lactamases [3]. These hydrolyse penicillins, broad-spectrum cephalosporin, and monobactams. Beta-lactamases species are ordinarily derived from TEM and SHV-type enzymes [4]. Extended spectrum beta lactamases (ESBLs)-producing Enterobacteriaceae have been responsible for various outbreaks of infection around the globe and pose challenging infection prevention problems [5]. In the previous 20 years, Gram-negative bacteria have elaborated their resistance to broad spectrum beta-lactam antibiotics [6]. Scientists have discovered more than 400 types of ESBLs, and majority of them reside in the Enterobacteriaceae family [7].

Uropathogenic Escherichia coli (UPEC) are one bacterium that can induce ESBL enzymes and can distinguish between phenotypic or genotypic methods [8]. The genotypic methods are more specific at identifying such resistant strains.ESBLs comprise many plasmid-mediated derivatives such as TEM, OXA, and SHV. Since 2000, a new group of ESBLs, called CTX-M (i.e., "active on CefoTaXime, first isolated in Munich"), has emerged [9]. Since then, CTX-M $\beta$ lactamases have been the predominant ESBL type worldwide [10]. This group of ESBLs has been associated with an extensive pattern of antimicrobial resistance to many antibiotics, including $\beta$-lactam agents such as penicillins, cephalosporins, monobactams, and carbapenems [11]. In addition, CTX-M-producing E. coli strains are often associated with co resistance to other large antimicrobial families such as aminoglycosides and fluoroquinolones. This increasing level of antimicrobial resistance of UPEC is of great concern since it can limit the therapeutic choices used for treating common bacterial infections such as UTIs and highlights the growing threat of the emergence of pan drug resistance in UPEC.

Molecular genotyping has been used along with phenotyping techniques to screen and confirm expression of antimicrobial drug resistance within a population [12]. Genotyping may help in controlling the spreading of pathogens, by tracing the origin of outbreaks. This area is often referred to as molecular epidemiology. The prevalence of ESBLs is increasingly being reported worldwide, and it varies according to geographic location and is directly linked to the use and misuse of antibiotics [13]. Incidentally the laboratory detection of ESBls can be more complex and is not routinely performed in most laboratories. In appreciation of the above-outlined issues, this study was aimed at determining the antimicrobial susceptibility patterns of a collection of clinical E. coli urine isolates, to phenotypically assess the ESBL carriage of these isolates and to characterize the ESBL genotypes (TEM, SHV, and CTX-M genes) of the isolates.

\section{Material and methods}

\subsection{Ethical approval}

This study was approved by the Ethics Committee of Nnamdi Azikiwe University Teaching Hospital, (NAUTH), Nnewi (Approval No. NAUTH/CS/66/VOL.11/149/2018/083).

\subsection{Sources and identification of Bacterial Isolates}

A total of 102 nonconsecutive, non-duplicate clinical Escherichia coli urine isolates were recovered from urinary tract infections suspects within the period of May to December, 2020 in Nnamdi Azikiwe University Teaching Hospital, Nnewi, Anambra State, Nigeria. Urine specimens were inoculated on CLED, EMB, and MacConkey using standard techniques. Plates were incubated overnight at $37{ }^{\circ} \mathrm{C}$ and inspected for growth [14]. Isolates were identified based on 
morphological and biochemical characteristics. Morphological characters include colony diameter, shape, texture, height, edge, color and reaction on the standard media used. Gram staining for all isolates was done. Routine biochemical tests i.e., lactose fermentation, indole production, Methyl red test, citrate utilization, urease and motility were tested according to Bergey's manual [15].

\subsection{Antibiotic susceptibility testing}

Antimicrobial susceptibility was determined by using Kirby-Bauer disk diffusion technique recommended by Clinical and Laboratory Standards Institute CLSI guidelines [16]. Antimicrobial agents used in this study were: Ampicillin (AMP$10 \mu \mathrm{g})$, Trimethoprim/Sulphamethoxazole(SXT-1.25/23.75 $\mu \mathrm{g})$, Ceftazidime(CAZ-30 $\mu \mathrm{g}), \quad$ Ceftriaxone(CRO-30 $\mu \mathrm{g})$,

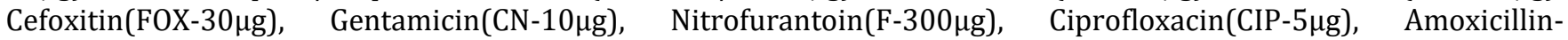

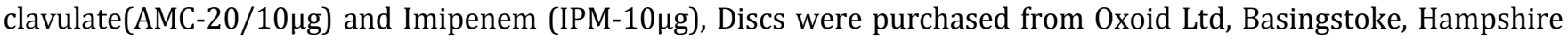
U.K.

\subsection{Phenotypic detection of ESBL production}

All the isolates which showed a diameter of less than $22 \mathrm{~mm}$ for ceftazidime(30 $\mu \mathrm{g})$ and less than $25 \mathrm{~mm}$ for ceftriaxone were identified as potential ESBL producers, then selected for ESBL production $[17,18]$. The ESBL production was tested by the Modified Double Disc Synergy Test (MDDST) by using a disc of amoxicillin-clavulanate (20/10 $\mu \mathrm{g})$ along with four cephalosporins; 3GC-cefotaxime, ceftriaxone, ceftazidime and 4GC-cefepime [18]. A lawn culture of the organisms was made on a Mueller-Hinton agar plate, as was recommended by CLSI guidelines [16]. A disc which contained amoxicillin-clavulanate $(20 / 10 \mu \mathrm{g})$ was placed at the centre of the plate. The discs of $3 \mathrm{GC}$ and $4 \mathrm{GC}$ were placed $15 \mathrm{~mm}$ and $20 \mathrm{~mm}$ apart respectively, centre to centre to that of the amoxicillin-clavulanic acid disc. Any distortion or increase in the zone towards the disc of amoxicillin-clavulanate was considered as positive for the ESBL production.

\subsection{Molecular (Genotypic) Characterization of ESBLs genes}

Out of the 76 confirmed ESBL phenotypes detected in this study, twenty (20) isolates were randomly selected for ESBL molecular characterization to detect blaCTX-M, blaTEM and blaSHV genes by PCR technique.

\subsubsection{Extraction of the E. coli DNA for PCR}

The extraction of the DNA was done using Quick-DNATM Miniprep Plus Kit (Zymo Research) according to manufacturer's instructions. The primers used and their amplicon sizes were as shown in Table 1.

Table 1 PCR Primers for ESBLs genes

\begin{tabular}{|l|c|l|c|c|}
\hline Target Gene & Primer name & Primer sequences(5'-3') & Product size (bp) & Reference \\
\hline blaCTX-M & $\begin{array}{l}\text { CTX-M-F } \\
\text { CTX-M-R }\end{array}$ & $\begin{array}{l}\text { CGCTTTGCGATGTGCAG } \\
\text { ACCGCGATATCGTTGGT }\end{array}$ & $500 / 512$ & 19 \\
\hline blaTEM & $\begin{array}{l}\text { TEM-F } \\
\text { TEM-R }\end{array}$ & $\begin{array}{l}\text { TCAACATTTCCGTGTCG } \\
\text { CTGACAGTTACCAATGCTTA }\end{array}$ & 800 & 19 \\
\hline blaSHV & $\begin{array}{l}\text { SHV-F } \\
\text { SHV-R }\end{array}$ & $\begin{array}{l}\text { CGCCTGTGTATTATCTCCCT } \\
\text { CGAGTAGTCCACCAGATCCT }\end{array}$ & 300 & 19 \\
\hline
\end{tabular}

\subsubsection{Amplification of DNA}

The PCR amplification was performed in 12.5 $\mu$ l of One Taq Quick-Load 2X Master Mix with Standard Buffer (New England Biolabs Inc.); $0.5 \mu$ l each of forward and reverse primers; $8.5 \mu$ l of Nuclease free water and $3 \mu$ l of DNA template was used to prepare $25 \mu \mathrm{l}$ reaction volume of the PCR cocktail. The reaction was gently mixed and transferred to an Eppendorf nexus gradient Mastercycler (Germany), for thermal cycling. The cycling parameters were at initial denaturation of $94^{\circ} \mathrm{C}$ for 5 minutes, denaturation of $94^{\circ} \mathrm{C}$ for $30 \mathrm{secs}$, annealing at $55^{\circ} \mathrm{C}$ for 1 min, followed by extension step of $72^{\circ} \mathrm{C}$ for 2 minutes and final extension of $72^{\circ} \mathrm{C}$ for 5 minutes for both CTX-M and TEM genes, then initial denaturation at $94^{\circ} \mathrm{C}$ for 5 minutes,denaturation of $94^{\circ} \mathrm{C}$ for 30 secs, Annealing at $54^{\circ} \mathrm{C}$ for 30 secs, followed by extension of $72^{\circ} \mathrm{C}$ for 1 minute and final extension at $72^{\circ} \mathrm{C}$ for 10 minutes for the SHV gene. 


\subsubsection{Preparation of agarose gel Electrophoresis}

After amplification the products were separated on a $2 \%$ agarose gel electrophoresis and amplified bands were visualized alongside a 100bp DNA ladder using gel documentation system with the help of ultraviolet light.

\subsubsection{Statistical Analysis}

Results were entered into an Excel spread sheet for Windows 9 and analysed using the Stata corp 16. Chi square test was used to determine the association or relationship between ESBL production and multi-drug resistance among the isolates. Results were presented in tables, bar chart and percentages. P value was considered at $95 \%$ confidence level and $P$ values less than $0.05(\mathrm{p}<0.05)$ were considered statistically significant.

\section{Results}

\subsection{Demographic Characteristics of study population}

In this study, a total of 102 Uropathogenic Escherichia coli (UPEC) isolates were obtained from urine samples of UTIs suspects that attended the Nnamdi Azikiwe University Teaching Hospital, Nnewi within the period of the study. Among these isolates, $63(61.76 \%)$ were from female participants, while 39 (38.24\%) were from male participants.Majority of the study participants are within the age range of 60-69 years (22.55\%) with a mean \pm SD of $50.6 \pm 19.364$ years. Demographic characteristics of patients are shown in Table 2.

Table 2 The socio-demographics of the study participants

\begin{tabular}{|c|c|c|}
\hline Socio-demographics & Frequency & Percentage $(\%)$ \\
\hline \multicolumn{3}{|l|}{ Age group } \\
\hline$<20$ years & 5 & 4.90 \\
\hline 20-29 years & 10 & 9.80 \\
\hline 30-39 years & 19 & 18.63 \\
\hline 40-49 years & 12 & 11.76 \\
\hline $50-59$ years & 14 & 13.73 \\
\hline $60-69$ years & 23 & 22.55 \\
\hline 70-79 years & 12 & 11.76 \\
\hline $80-89$ years & 7 & 6.86 \\
\hline Mean \pm SD & $50.6 \pm 19.364$ & \\
\hline \multicolumn{3}{|l|}{ Gender } \\
\hline Females & 63 & 61.76 \\
\hline Males & 39 & 38.24 \\
\hline \multicolumn{3}{|l|}{ Ward } \\
\hline $\mathrm{A} / \mathrm{E}$ & 18 & 17.65 \\
\hline ANC & 1 & 0.98 \\
\hline CHER & 1 & 0.98 \\
\hline CHOP & 1 & 0.98 \\
\hline ENDO & 2 & 1.96 \\
\hline FMW & 8 & 7.84 \\
\hline FSW & 1 & 0.98 \\
\hline GOPD & 10 & 9.80 \\
\hline
\end{tabular}




\begin{tabular}{|l|c|c|}
\hline GYNAE & 6 & 5.88 \\
\hline L/W & 5 & 4.90 \\
\hline MMW & 7 & 6.86 \\
\hline MOP & 13 & 12.75 \\
\hline MSW & 4 & 3.92 \\
\hline NHIS & 8 & 7.84 \\
\hline PMW & 1 & 0.98 \\
\hline PSW & 1 & 0.98 \\
\hline SOP & 12 & 11.76 \\
\hline URO & 2 & 1.96 \\
\hline USOP & 1 & 0.98 \\
\hline TOTAL & 102 & 100 \\
\hline
\end{tabular}

A /E; Accident and emergency ward, ANC; Antenatal clinic, FSW; Female surgical ward, MSW; Male surgical ward, FMW; Female medical ward, MMW; Male medical ward, SOP; Surgical outpatient, NHIS; National health insurance scheme, PSW; Pediatric surgical ward, PMW; Pediatric medical ward, MOP; Medical outpatient, GOPD; General outpatient department, CHER; Children emergence, URO; Urology ,USOP; Urology surgery outpatient, ENDO; Endocrinology, L/W; Lying-in ward, CHOP; Children outpatient, GYNAE; Obstetrics and Gynaecology.

\subsection{Antimicrobial Susceptibility Profiles}

The antibiotic susceptibility testing results are shown in Table 3. Among the ten different antibiotics tested, imipenem was the most active agent with $48.04 \%$ and $28.4 \%$ susceptible and intermediately susceptible respectively. Out of the 102 isolates, 101(99.02\%), 67(65.7\%), and 56(54.9\%) were resistant to ampicillin, amoxicillin-clavulanic acid, and gentamycin respectively. The resistance rates for ceftazidime, ceftriaxone, cefoxitin, trimethoprim-sulfamethoxazole and imipenem were $81.4 \%, 82.4 \%, 46.1 \%, 97.1 \%$ and $23.5 \%$ respectively. Furthermore, $88.2 \%$ and $46.1 \%$ of the isolates were resistant to ciprofloxacin and nitrofurantoin respectively.

Table 3 The antibiotic susceptibility pattern of the different E. coli isolates tested in this study

\begin{tabular}{|l|c|c|c|}
\hline \multirow{2}{*}{ Antibiotic } & \multicolumn{3}{|c|}{ Sensitivity Pattern (\%) } \\
\cline { 2 - 4 } & Susceptible (\%) & Intermediate (\%) & Resistant (\%) \\
\hline AMP & $1(0.98)$ & Nil & $101(99.02)$ \\
\hline AMC & $14(13.73)$ & $21(20.59)$ & $67(65.69)$ \\
\hline CN & $46(45.10)$ & Nil & $56(54.90)$ \\
\hline CAZ & $11(10.78)$ & $8(7.84)$ & $83(81.37)$ \\
\hline CRO & $6(5.88)$ & $12(11.76)$ & $84(82.35)$ \\
\hline FOX & $38(37.25)$ & $17(16.67)$ & $47(46.08)$ \\
\hline SXT & Nil & $3(2.94)$ & $99(97.06)$ \\
\hline IPM & $49(48.04)$ & $29(28.43)$ & $24(23.53)$ \\
\hline CIP & Nil & $12(11.76)$ & $90(88.24)$ \\
\hline NIT & $38(37.25)$ & $17(16.67)$ & $47(46.08)$ \\
\hline
\end{tabular}

\subsection{Multi-drug resistance}

Hundred (98.04\%) of the isolates were found to be multidrug resistant, while two (1.96\%) isolates were non-Multidrug resistance (Table 4). Of the 102 UPEC isolates used in this study, 100 isolates were resistant to at least one agent in three or more antibiotic class; thus, indicating that most of the isolates were ESBLs-producers. 
Table 4 The drug resistance pattern of the different $E$. coli isolates used in the study

\begin{tabular}{|l|c|c|}
\hline Drug resistance pattern & Frequency & Percentage \\
\hline MDR & 100 & 98.04 \\
\hline Non-MDR & 2 & 1.96 \\
\hline Total & 102 & 100 \\
\hline
\end{tabular}

MDR; Multi drug resistance

\subsection{ESBL Prevalence}

With regard to ESBL production, the phenotypic detection method using the Modified Double Disc Synergy Test (MDDST) revealed that 76(74.5\%) of all the isolates were ESBL producers (positive), while 26(25.5\%) were non-ESBL producers (negative).

\subsection{Molecular characterization of ESBL genes}

Twenty (20) ESBL-producing E. coli isolates were randomly chosen and tested for the production of the ESBL genes (blaстх-м, blaтем, and blasнv) by PCR. Information on the PCR primers used for gene detection is shown in Table 1. Amplified PCR-products for bla CTX-M, TEM and SHV genes gave molecular weights (band sizes) of 500/512,860 and 300 base pairs respectively as shown in Figure 1.

A.

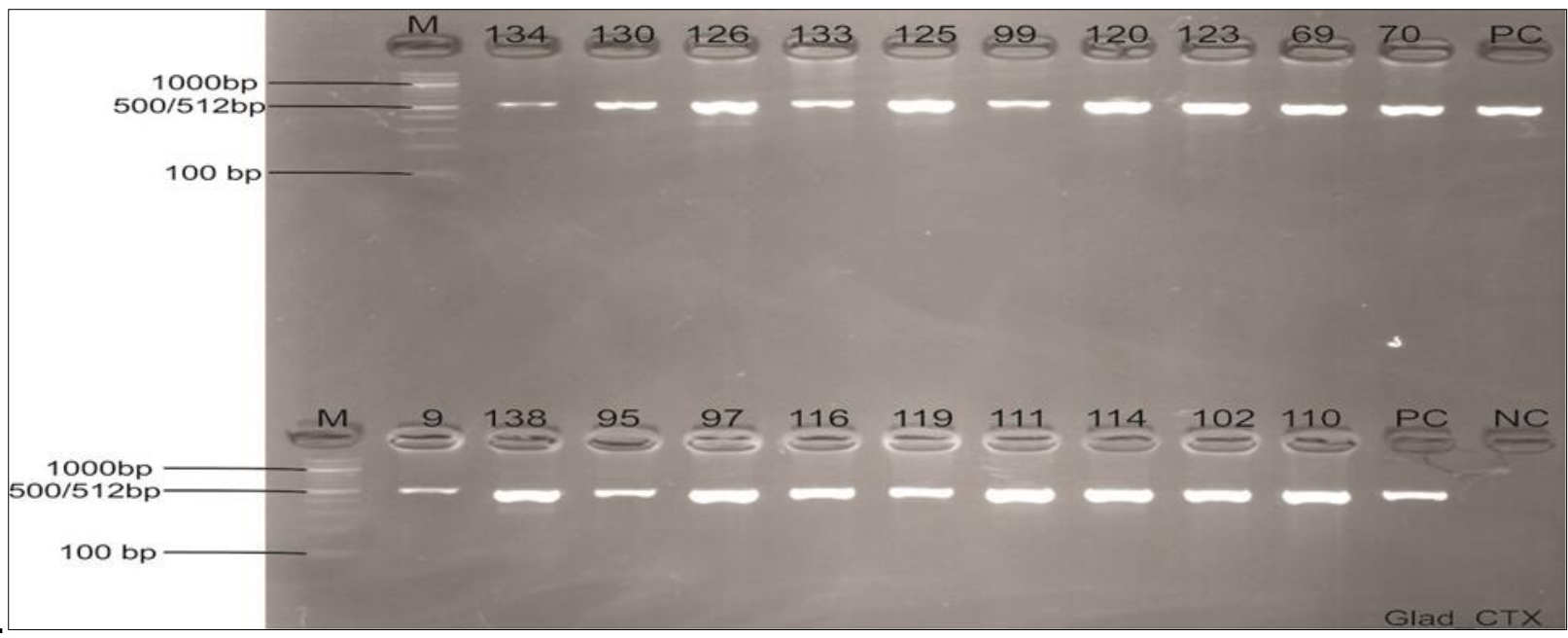

B.

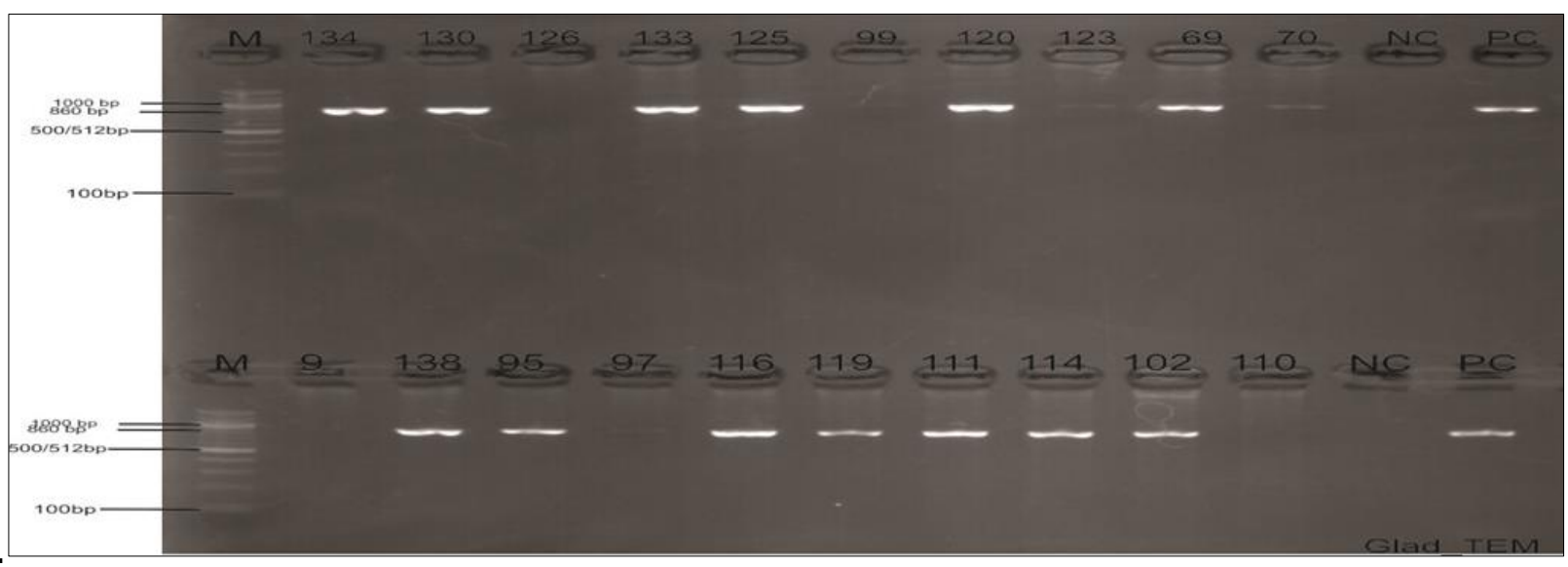




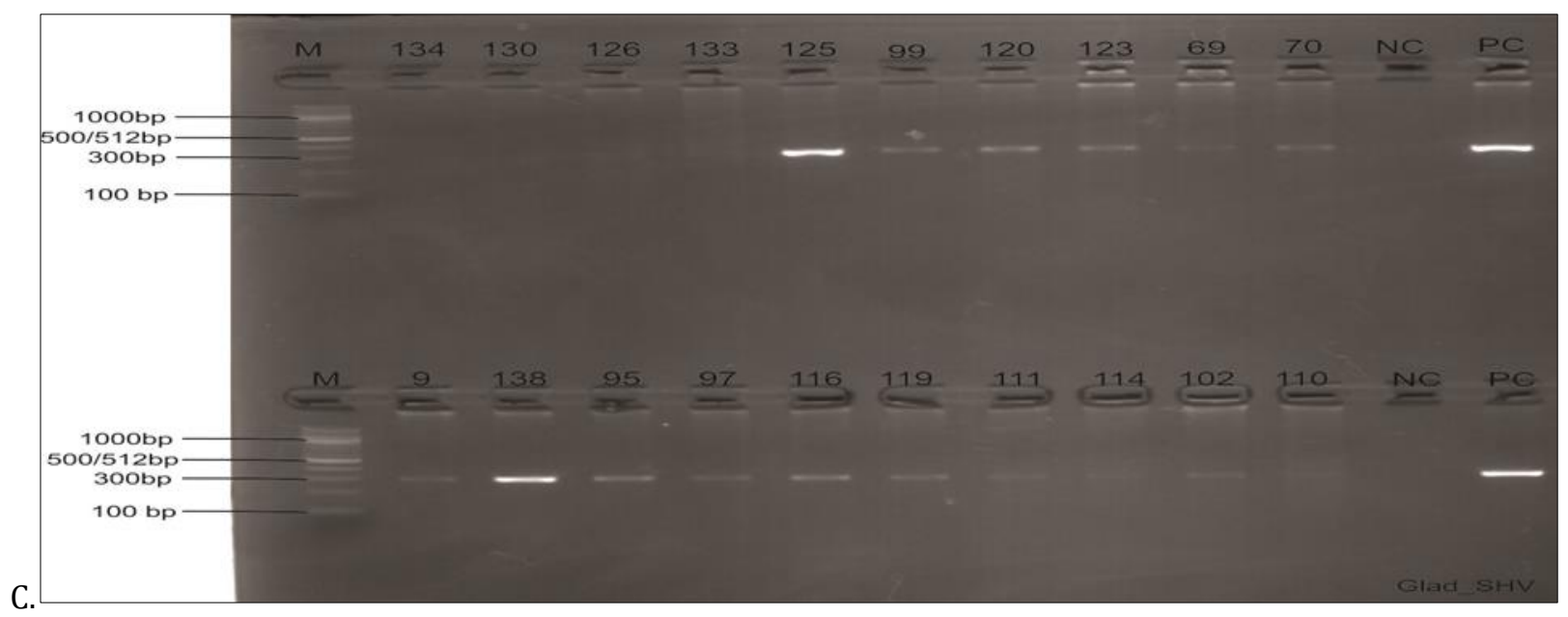

Figure 1 Amplified products of CTX-M, TEM and SHV genes. 2.0\% Agarose gel analysis of PCR amplified fragment of (A) bla CTX-M (510/512bp) using CTX-M-F and CTX-M-R primers, (B) blaTEM (860bp) using TEM-F and TEM-R primers, (C)bla SHV (300bp) using the SHV-F and SHV-R primers. The 20 different lanes which were represented by the isolates project identification numbers are the PCR products of the ESBL genes from E. coli isolates. Lane M is the molecular weight ladder (DNA markers) spanning from 100-1000bp; NC and PC arePCR products of E.coli negative and positive controls respectively.

\subsection{The prevalence of the three different ESBL genes}

This study showed that CTX-M gene was the predominant type (20/20; 100\%) while TEM and SHV genes were less predominant (17/20; 85\% and 16/20; 80\%, respectively). Figure 2 below showed the distribution of the ESBL genes in different wards of the hospital.

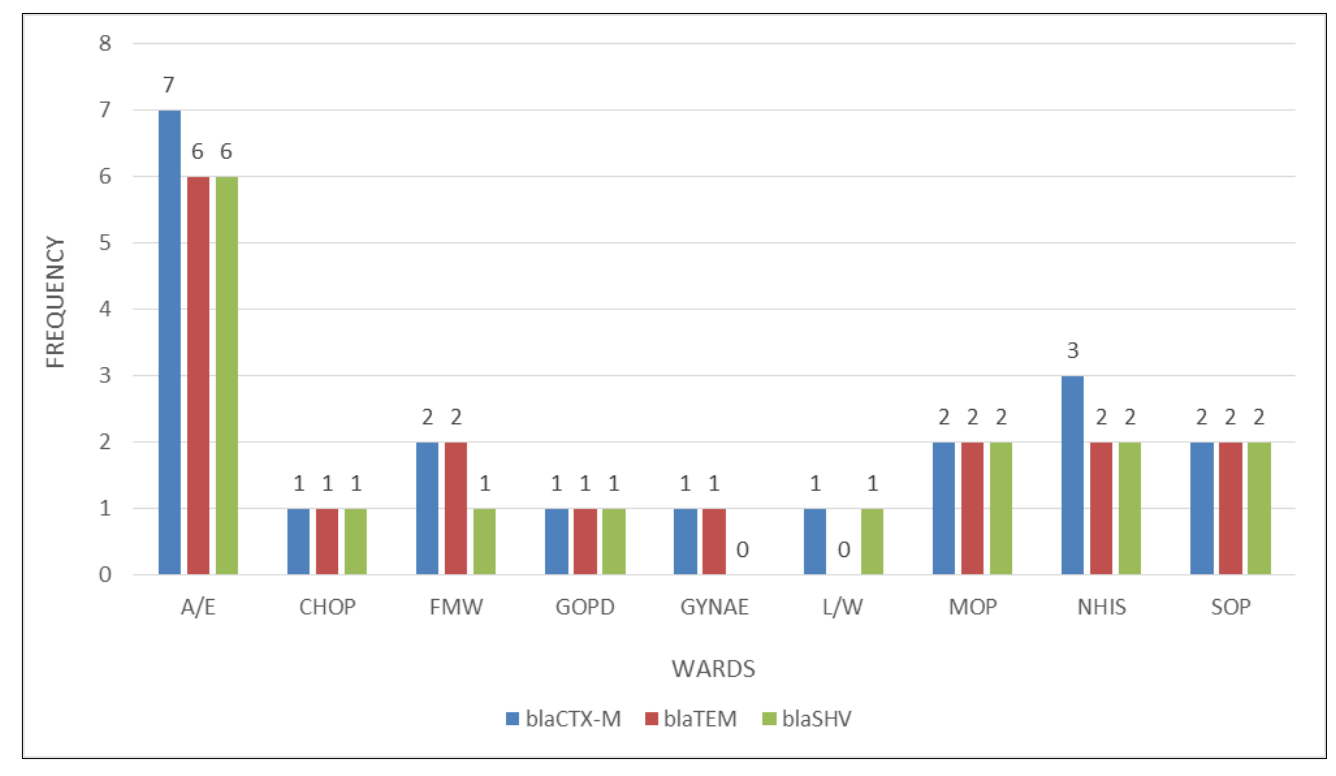

Figure 2 A column bar chart showing the distribution of the ESBL genes in the different wards in NAUTH, Nnewi.

\subsection{Genotypic patterns of ESBLs}

Analysis of the amplified products of the 20 E. coli ESBLs producers using the specific primers revealed that four genotype patterns were obtained (Table 5). These results showed that the most prevalent genotype was SHV+TEM+CTX-M (70.0\%) combination, followed by TEM+CTX-M (15.0\%) combination. 
Table 5 ESBLs genotype patterns among the E.coli isolates

\begin{tabular}{|l|c|c|}
\hline ESBLs genotype & Number of isolates & Percentage \\
\hline blaCTX-M only & 1 & 5.0 \\
\hline blaSHV only & 0 & 0 \\
\hline blaTEM only & 0 & 0 \\
\hline blaTEM and blaSHV & 0 & 0 \\
\hline blaTEM and blaCTX-M & 3 & 15.0 \\
\hline blaSHV and blaCTX-M & 2 & 10.0 \\
\hline blaSHV + blaTEM + blaCTX-M & 14 & 70.0 \\
\hline Total & 20 & 100.0 \\
\hline
\end{tabular}

\section{Discussion}

The emergence of Multidrug resistant (MDR) E. coli strains and the progressive rise in antimicrobial resistance threatens the effective treatment of UTIs leading to increased morbidity, prolonged hospital stay, increase in the cost of treatment and disease related mortality [20]. Extended spectrum beta- lactamases (ESBLs) production is an important mechanism used by these pathogens to jeopardize UTI treatment options; thus, early detection of the characteristics of antimicrobial resistance of these pathogens in a particular region will help to devise strategies that will reduce the extensive misuse of antimicrobial agents and prevent the emergence and subsequent spread of such MDR isolates.

The results of the antibiotic susceptibility showed that the isolates were highly resistant to ampicillin (99.0\%), trimethoprim-sulfamethoxazole (97.1\%), ciprofloxacin (88.2\%), ceftriaxone(82.4\%), ceftazidime(81.4\%), amoxicillinclavunate $(65.7 \%)$. This finding is in agreement with other studies [21-23]. Alqasim and co discovered in their study that UPEC isolates have shown an increased level of antimicrobial resistance to frontline antibiotics such as trimethoprimsulfamethoxazole and ciprofloxacin [17]. The high level of antimicrobial resistance seen could be attributed to the inappropriate and excessive use of these agents in the empirical treatment of UTIs [24]. Also imipenem in this study showed reduced susceptibility of $48.04 \%$, intermediately susceptible (28.43\%), and resistance rate of $23.5 \%$. This is in contrast to other findings such as $[23,15,18,14,24]$ with high susceptibility (for imipenem) rates of $100,98,100,100$ and $97.1 \%$ respectively. However, the finding is in conformity with studies of [25 - 26] with a resistance of $17.32 \%$ and $22 \%$ respectively. The reduced susceptibility of imipenem seen in this study might be due to the production of carbapenamase enzyme by some of these isolates. This enzyme is capable of hydrolyzing carbapenems antibiotic group. The carbapenems (imipenem, meropenem, doripenem, e.t.c), which are the last resort in the effective treatment of severe ESBL-producing E. coli infections, have recently witnessed rise in resistance by E. coli strains that produced carbapenem-hydrolyzing enzymes [27].

The prevalence of multiple drug resistance (MDR) among the studied isolates was $98.04 \%$. This is considered to be very high and is in accordance with the reported findings of $85-100 \%$ in various parts of Nigeria and other African countries[28- 32 ]. Hassan et al and Elsayed et al [33,14] also reported 100\% and 95\% MDR phenotypes respectively. These findings indicate that most of these isolates are ESBL producers capable of causing multidrug resistance to drugs; thereby jeopardizing UTIs treatment.

The genotypic (molecular) detection of the resistant ESBL genes among the randomly selected twenty ESBL positive isolates in this study revealed that the bla CTX-M gene was the predominant type (100\%), while TEM and SHV-types were $85 \%$ and $80 \%$ respectively. This has been reported in other studies done in Nigeria $[34,35,36,23]$ and studies done across the globe $[22,37,38,17]$. Studies in Iraq and neighboring countries have declared that CTX-M type was the predominant gene type in both E. coli and Klebsiella pneumonia [39] and currently, CTX-M enzymes have replaced the traditional ESBL types such as SHV and TEM enzymes as the predominant ESBL type in E. coli[6]. However, studies from Turkey and India revealed that TEM was the predominant type [40].

The analysis of the PCR amplified products of the 20 isolates revealed that four genotype patterns of ESBLs existed among the isolates. Combination of SHV+TEM+CTX-M was the most prevalent genotype (70\%), followed by the genotype combination TEM+CTX-M (15\%). Further illustrations are seen in the study. The multiple genes (SHV, TEM and CTX-M) harboured by some of these isolates in their genome suggested the carriage of resistance plasmids [37]. A 
study by Polse et al., revealed six genotype patterns [22]. This might be because larger sample size of 55 isolates was used, but only 20 isolates was used in this study. The presence of more than one resistance ESBL genes in some of the isolates means that the ESBL-producing strains may be related to a complex antimicrobial resistance [22]; this has resulted to co-resistance to other antibiotics group apart from the $\beta$-lactams antibiotic groups. The TEM gene is a broad spectrum ESBLs that is always combined with CTX-M on the same plasmid [22]. The occurrence of SHV+TEM+CTX-M combination can cause resistance to carbapenems [41], as seen in the study. This is worrisome and more serious for the community, because carbapenems which is regarded as the antibiotic of last choice and mainstay of treatment used against infections caused by ESBLs are equally experiencing setback gradually due to emergence of carbapenamaseproducing strains.

\section{Conclusion}

This study found a high rate of ESBL production (74.5\%) in Escherichia coli isolates with high multi drug resistance pattern. Clinical Microbiology laboratories should routinely incorporate ESBL detection methods for continuous surveillance of multidrug resistant isolates and antibiograms to guide empirical therapy. Effective hospital-based infection prevention and control and antibiotic stewardship programs aimed at limiting the spread and emergence of resistant isolates should be instituted in our health-care facilities.

\section{Compliance with ethical standards}

\section{Acknowledgments}

We thank the management of Nnamdi Azikiwe Teaching Hospital Hospital, Nnewi, Anambra State for giving approval for this study. Also, we are grateful to Prof. N.R Agbakoba for supervising the research work.

\section{Disclosure of conflict of interest}

All authors declare that they have no conflict of interest to disclose.

\section{Statement of ethical approval}

The study protocol was reviewed and approved by the Research Ethics committee at Nnamdi Azikiwe University Teaching Hospital, Nnewi, Anambra State.

\section{Authors' Contributions}

Conceptualization: Nneka R. Agbakoba; Investigation: Ifeoma G. Nwafuluaku; Methodology: Ifeoma G. Nwafuluaku, Simon N. Ushie; Supervision: Nneka R. Agbakoba; Writing-original draft: Ifeoma G. Nwafuluaku; Writing-review and editing: Eucharia A. Dilibe, Ifeoma G. Nwafuluaku, Simon N. Ushie, Nneka R. Agbakoba.

\section{Abbreviations}

MDR: Multidrug-resistance

UPEC: Uropathogenic Escherichia coli

E. coli: Escherichia coli

PCR: Polymerase Chain Reaction

MDDST: Modified Double Disc Synergy Test

ESBLs: Extended-Spectrum beta-lactamases

TEM: Temoneira (an ESBL enzyme named after a Greek patient)

SHV: Sulfhydryl variable

CTX-M: An extended-spectrum beta-lactamase with greater activity against

cefotaxime: CTX for cefotaximase, and M for Munich.

NAUTH: Nnamdi Azikiwe University Teaching Hospital, Nnewi.

UTIs: Urinary Tract infections

CLSI: Clinical and Laboratory Standards Institute

Bla: Beta lactamase

CLED: Cysteine lactose Electrolyte Deficient

EMB: Eosine Methylene Blue 


\section{References}

[1] Bagshaw SM, Laupland KB. Epidemiology of intensive care unit-acquired urinary tract infections. Current Opinion in Infectious Diseases. 2006;19(1):67-71.

[2] Sabir S, Anjum AA, Ijaz T, Ali MA, Khan MR, Nawaz M. Isolation and antibiotic susceptibility of Escherichia coli from urinary tract infections in a tertiary care hospital. Pakistan Journal of Medical Sciences. 2014; 30(2): 389392.

[3] Cantón R, Oliver A, Coque TM, Varela M, Del C, Pérez-Díaz JC, Baquero F. Epidemiology of extended-spectrum $\beta$ lactamase-producing Enterobacter isolates in a Spanish hospital during a 12-year period. Journal of Clinical Microbiology. 2002; 40(4):1237-43.

[4] Paterson DL, Bonomo RA. Clinical Update Extended-Spectrum Beta- Lactamases : a Clinical Update. Clinical Microbiology Reviews. 2005; 18(4): 657-686.

[5] Teklu DS, Negeri AA, Legese MH, Bedada TL, Woldemariam HK, Tullu KD. Extended-spectrum beta-lactamase production and multi-drug resistance among Enterobacteriaceae isolated in Addis Ababa, Ethiopia. Antimicrobial Resistance and Infection Control. 2019; 8(1):1-12.

[6] Cantón R, Coque TM. The CTX-M $\beta$-lactamase pandemic. Current Opinion in Microbiology. 2006; 9(5):466-475.

[7] Latifpour M, Gholipour A, Damavandi MS. Prevalence of extended-spectrum beta-lactamase-producing Klebsiella Pneumoniae isolates in nosocomial and community-acquired urinary tract infections. Jundishapur Journal of Microbiology. 2016; 9(3):1-8.

[8] Garrec H, Drieux-Rouzet L, Golmard JL, Jarlier V, Robert J. Comparison of nine phenotypic methods for detection of Extended-spectrum $\beta$-lactamase production by Enterobacteriaceae. Journal of Clinical Microbiology.2011; 49(3):1048-57.

[9] Peirano G, Pitout JDD. Molecular epidemiology of Escherichia coli producing CTX-M $\beta$-lactamases: the worldwide emergence of clone ST131 025:H4. International Journal of Antimicrobial Agents. 2010; 35(4): 316-321.

[10] Pitout JDD, Laupland KB. Extended Spectrum $\beta$ lactamase Producing Enterobacteriaceae: An Emerging public Health concern. Lancet infectious Diseases. 2008; 8:159-166.

[11] Johnson TJ, Hargreaves M, Shaw K, Snippes P, Lynfield R, Aziz M, Price LB. Complete genome sequence of a carbapenem-resistant extraintestinal pathogenic Escherichia coli strain belonging to the sequence type 131 H30R subclade. Genome Announcements. 2016; 3(2):2014-15.

[12] Alyamani EJ, Khiyami AM, Booq RY, Majrashi MA, Bahwerth FS, Rechkina E. The occurrence of ESBL-producing Escherichia coli carrying aminoglycoside resistance genes in urinary tract infections in Saudi Arabia. Annals of Clinical Microbiology and Antimicrobials. 2017; 16(1): 1-13.

[13] Giwa F, Ige O, Haruna D, Yaqub Y, Lamido T, Usman S. Extended-Spectrum beta-lactamase production and antimicrobial susceptibility pattern of uropathogens in a Tertiary Hospital in Northwestern Nigeria. Annals of Tropical Pathology. 2018; 9(1):11-16.

[14] Elsayed TI, Ismail HA, Elgamal SA, Gad AHA. The Occurrence of Multidrug Resistant E.coli which Produce ESBL and cause Urinary Tract Infections. Journal of Applied Microbiology and Biochemistry. 2017;1(2):1-8.

[15] Holt JG, Krieg NR, Sneath PHA, Stanley JT, William ST. Bergey's Manual of Determinative Bacteriology.9th ed. Baltimore:Williams \& Wilikins. 1994; 786-788.

[16] Clinical and Laboratory Standard Institute. Performance standards for antimicrobial susceptibility testing; 30th informational Supplement. 2020; (M100-S30).

[17] Alqasim A, Abu Jaffal A, Alyousef AA. Prevalence of multidrug resistance and extended-spectrum $\beta$-Lactamase carriage of clinical uropathogenic Escherichia coli isolates in Riyadh, Saudi Arabia. International Journal of Microbiology. 2018; 1-9.

[18] Kaur J, Chopra S, Sheevani N, Mahajan G. Modified double disc synergy test to detect ESBL production in urinary isolates of Escherichia coli and Klebsiella pneumoniae. Journal of Clinical and Diagnostic Research. 2013;7(2):229-233.

[19] Molecular Research Foundation for Students and Scientists. PCR Protocol for Detection of ESBL Genes. 2019; 18. 
[20] Picozzi S, Ricci C, Gaeta M, MacChi A, Dinang E, Paola G, Tejada, Costa, E, Bozzini G, Casellato S,Carmignani L. Do we really know the prevalence of multi-drug resistant Escherichia coli in the territorial and nosocomial population? Urology Annals.2013; 5(1): 25-29.

[21] Al-Agamy MH, Shibl AM, Hafez MM, Al-Ahdal MN, Memish ZA,Khubnani H. Molecular characteristics of extendedspectrum $\beta$-lactamase-producing Escherichia coli in riyadh: Emergence of CTX-M-15-producing E. coli ST131. Annals of Clinical Microbiology and Antimicrobials. 2014; 13(1): 1-7.

[22] Polse RF, Yousif SY, Assafi MS. Prevalence and molecular characterization of Extended spectrum betaLactamases-producing uropathogenic Escherichia coli isolated in Zakho, Iraq. Journal of Microbiology and infectious Diseases. 2016; 6(4):163-167.

[23] Nwafia IN, Ohanu ME, Ebede SO, Ozumba UC. Molecular detection and antibiotic resistance pattern of extendedspectrum beta-lactamase producing Escherichia coli in a Tertiary Hospital in Enugu, Nigeria. Annals of Clinical Microbiology and Antimicrobials. 2019; 18(1): 1-7.

[24] Abduzaimovic A, Aljicevic M, Rebic V, Vranic SM, Sestic S. Antibiotic Resistance in Urinary Isolates of Escherichia coli. Materia Socio-Medica Journal. 2016; 28(6): 416-419.

[25] Gupta E, Mohanty S, Sood S, Dhawan B, Das BK, Kapil A. Emerging resistance to carbapenems in a tertiary care hospital in North India. Indian Journal of Medical Research. 2006; 124(1): 95-98.

[26] Kamel A, Naser J, Awni A, Ghaleb A, Elena A. Molecular characterization of Escherichia coli isolates from patients with urinary tract infections in Palestine. Journal of Medical Microbiology.2014; 63:229-234.

[27] Muhammad MH, Swedan S. Molecular and Phenotypic Characterization of Carbapenem Resistance and Extended Spectrum Beta- Lactamases Among Urinary Escherichia coli Isolates. International Journal of Science and Technology.2014; 5(9):1-14.

[28] Aboderin OA, Abdu LR, Odetoyin BW, Lamikanra A. Antimicrobial resistance in Escherichia coli strains from urinary tract infections. Journal of the National Medical Association. 2009; 101(12): 1268-73.

[29] Olorunmola FO, Kolawole DO, Lamikanra AO. Antibiotic resistance and virulence properties in Escherichia coli strains from cases of urinary tract infections. African Journal of Infectious Diseases.2013; 7(1):1-7.

[30] Anago E, Ayi-Fanou L, Akpovi CD, Hounkpe WB, Agassounon D, Tchibozo M, Bankole HS, Sanni A. Antibiotic resistance and genotype of beta-lactamase producing Escherichia coli in nosocomial infections in Cotonou, Benin. Annals of Clinical Microbiology and Antimicrobials. 2015; 14(5):1-6.

[31] Emmanuel U. Phenotypic Characterization and Comparative Study on ESBL-producing E. coli of Clinical Origin. International Journal of Sciences. 2016; 2(2): 27-31.

[32] Salah FD, Diagbouga S, Dabire AM. First Detection of Resistance Genes Encoding Extended Spectrum BetaLactamase Producing Escherichia coli at Lome, Togo. Archives of Clinical Microbiology. 2016; 7(6):32(1-7).

[33] Hassan S, Jamal S, Kama M. Occurrence of multidrug resistant and ESBL producing E. coli causing urinary tract infections. Journal of Basic Applied Sciences. 2011; 7(S1):39-43.

[34] Raji MA, Jamal W, Ojemeh O, Rotimi VO. Sequence analysis of genes mediating extended-spectrum beta-lactamase (ESBL) production in isolates of Enterobacteriaceae in a Lagos Teaching Hospital, Nigeria. BioMed Central Infectious Diseases.2015; 15(1): 7-12.

[35] Ogefere HO, Aigbiremwen PA, Omoregie R. Extended-spectrum beta-lactamase (esbl)-producing Gram-negative isolates from urine and wound specimens in a tertiary health facility in Southern Nigeria. Tropical Journal of Pharmaceutical Research. 2015; 14(6):1089-94.

[36] Rani VS, Rao RK, Ravinder S, Kanakadurga P. Prevalence of Extended Spectrum Beta Lactamase ( ESBL ) Producing Pseudomonas aeruginosa Isolates from Burns Patients. International Journal of Contemporary Medical Research. 2016; 3(5):1297-1300.

[37] Mashwal FA, El Safi SH, George SK, Adam AA, Jebakumar AZ. Incidence and molecular characterization of the Extended Spectrum beta lactamase-producing Escherichia coli isolated from urinary tract infections in Eastern Saudi Arabia. Saudi Medical Journal. 2017;38(8): 811-815.

[38] Jena J, Sahoo RK, Debata NK, Subudhi E. Prevalence of TEM, SHV, and CTX-M genes of extended-spectrum $\beta$ lactamase-producing Escherichia coli strains isolated from urinary tract infections in adults. 3 Biotech. 2017; $7(244): 1-7$. 
[39] Barguigua A, Otmani F, El-Talmi M, Bourjilat F, Haouzane F, Zerouali K, Timinouni M. Characterization of Extended-spectrum $\beta$-lactamase-producing Escherichia coli and Klebsiella pneumoniae isolates from the community in Morocco. Journal of Medical Microbiology. 2011; 60(9):1344-52.

[40] Bali EB, Açlk L, Sultan N. TEM, CTX-M and Extended-spectrum -lactamase and Klebsiella isolates in a Turkish hospital. African Journal of Microbiology Research. 2010; 4(8): 650-654.

[41] ManoharanA, Premalatha K, Chatterjee S,MathaiD. Correlation of TEM, SHV and CTX-M extended-spectrum beta lactamases among Enterobacteriaceae with their in vitro antimicrobial susceptibility. Indian Journal of Medical Microbiology. 2011; 29(2): 161-164. 